\title{
Choice of immobilization of stereotactic body radiotherapy in lung tumor patient by BMI
}

Guofu Chen ${ }^{1}$, Baiqiang Dong ${ }^{1,2}$, Guoping Shan ${ }^{1}$, Xiuqin Zhang ${ }^{3}$, Huarong Tang ${ }^{1}$, Yuchen Li ${ }^{1}$, Zhenhua Wang ${ }^{1}$,

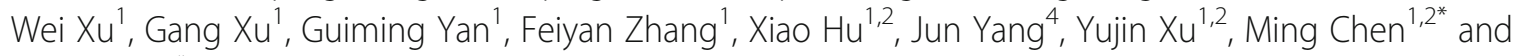
Jin Wang ${ }^{1,2^{*}}$

\begin{abstract}
Background: An accurate, reproducible, and comfortable immobilization device is essential for stereotactic radiotherapy (SBRT) in patients with lung cancer. This study compared thermoplastic masks (TMP) and vacuum cushion (VCS) system to assess the differences in interfraction and intrafraction setup accuracy and the impact of body mass index (BMI) with respect to the immobilization choice.

Methods: This retrospective study was conducted on patients treated with lung SBRT between 2012 and 2015 at the Zhejiang cancer hospital. The treatment setup accuracy was analyzed in 121 patients. A total of 687 cone beam computed tomography (CBCT) scans before treatment and 126 scans after treatment were recorded to determine the uncertainties, and plan target volume margins. Data were further stratified and analyzed by immobilization methods and patients' BMI. The t-test (Welch) was used to assess the differences between the two immobilization systems when stratified by the patients' BMI.

Results: For patients with $\mathrm{BMI} \geq 24$, the mean displacements for the TMP and VCS systems were $1.4 \pm 1.2$ vs. $2.4 \pm 2.0 \mathrm{~mm}$ at medial-lateral (ML) direction $(p<0.001) ; 2.0 \pm 1.9$ vs. $2.0 \pm 1.9 \mathrm{~mm}$ at cranial-caudal $(C C)$ direction $(p=0.917)$; and $2.4 \pm 1.4$ vs. $2.6 \pm 2.1 \mathrm{~mm}$ at anterior-posterior (AP) direction, $(p=0.546)$. The rate of acceptable errors increased dramatically when immobilized by TMP. In the case of patients with $\mathrm{BMI}<24$, the mean displacements for the TMP and VCS systems were $1.8 \pm 1.4$ vs. $2.1 \pm 1.8 \mathrm{~mm}$ at ML direction $(p=0.098)$; $2.9 \pm 2.3$ vs. $2.2 \pm 2.2 \mathrm{~mm}$ at CC direction $(p=0.001)$; and $1.8 \pm 1.8$ vs. $2.3 \pm 2.0 \mathrm{~mm}$ at $C C$ direction, $(p=0.006)$. The proportion of acceptable errors increased after immobilization by VCS. No difference was detected in the intrafraction setup error by different immobilization methods.

Conclusions: The immobilization choice of SBRT for lung tumors depends on the BMI of the patients. For patients with $\mathrm{BMI} \geq 24$, TMP offers a better reproducibility with significantly less interfractional setup displacement than VCS, resulting in fewer CBCT scans. However, VCS may be preferred over TMP for the patients with $\mathrm{BMI}<24$. Therefore, an optimal immobilization system needs to be considered in different BMI groups for lung SBRT.
\end{abstract}

Keywords: Lung cancer, SBRT, Interfraction motion, Immobilization, BMI

\footnotetext{
* Correspondence: wangjin@zjcc.org.cn; chenming@zjcc.org.cn

'Department of Radiation Oncology, Zhejiang Cancer Hospital, 1st Banshan

East Road, Hangzhou 310022, China

Full list of author information is available at the end of the article
}

(c) The Author(s). 2019 Open Access This article is distributed under the terms of the Creative Commons Attribution 4.0 International License (http://creativecommons.org/licenses/by/4.0/), which permits unrestricted use, distribution, and reproduction in any medium, provided you give appropriate credit to the original author(s) and the source, provide a link to the Creative Commons license, and indicate if changes were made. The Creative Commons Public Domain Dedication waiver (http://creativecommons.org/publicdomain/zero/1.0/) applies to the data made available in this article, unless otherwise stated. 


\section{Background}

In recent years, multiple studies demonstrated that the overall survival of patients undergoing stereotactic body radiation therapy (SBRT) is similar to that of surgical resection in operable stage I non-small cell lung cancer (NSCLC) [1-3]. In addition, for inoperable early-stage lung cancer, SBRT is a critical alternative therapy [4]. Also, it is one of the major local therapies for oligometastatic lung tumors [5]. SBRT is characterized with few treatment fractions and high-dose in each treatment. The accurate image guidance restricted the high-dose radiation to the target areas, while doses outside the target areas declined rapidly to avoid damage to the critical adjacent organs [6-8].

To reduce the tissue toxicity maximally and ensure the accuracy of implementation, currently four-dimensional computed tomography (4D-CT) is used to eliminate the effects of respiratory motion. Subsequently, the PTV margins are minimized, and setup errors between fractionated radiations are corrected using cone-beam $\mathrm{CT}$ $(\mathrm{CBCT})$ in the premise of accurate radiation on the target areas. The setup errors in the medial-lateral (ML) direction, the cranial-caudal (CC) direction, and the anterior-posterior (AP) direction are limited within 2-5 $\mathrm{mm}$. If the positional discrepancies are substantial, CBCT verification should be repeated after the couch adjustment [9]. Therefore, the repetitive CBCT scans extend the overall treatment duration, along with additional cost and workload of the technicians [10]. The longer the treatment duration, the more likely the displacements in patients to occur during SBRT [11]. However, the interfractional setup errors and intrafractional motions should be avoided. In addition to the factors such as co-operation of patients and the experience of technicians, the selection of immobilization method is also crucial [12].

Thermoplastic masks (TMP) and vacuum cushions (VCS) are commonly used immobilization devices in SBRT; however, there are only a few studies comparing the two devices. Navarro-Martin et al. demonstrated that the setup errors of the two devices TMP were smaller. Markedly, the TMPs were favored by the technologists [10]. Nevertheless, the body shape and physical condition of the patients, as well as compliance with the advice of the doctors differed in a practical setting. Thus, one immobilization device might not be suitable for all patients, and different devices might be used based on the characteristics of the patients.

Therefore, the present study assessed the interfraction and intrafraction setup errors by different immobilizations in patients with lung tumors who underwent SBRT. Moreover, the effects of patient-related factors and immobilization devices on the interfraction and intrafraction setup errors were analyzed. Herein, we hypothesized that the immobilization devices were selected based on the characteristics of patients in order to ensure the accurate implementation of SBRT.

\section{Methods \\ Patient data}

The present study was approved by the Ethics Committee and Institutional Review Board of Zhejiang Cancer Hospital (belongs to Zhejiang Cancer Hospital; the committee's reference Number: IRB-2018-153(Ke)). The medical records of NSCLC patients, who underwent SBRT in Zhejiang Cancer Hospital from January 2012 to September 2015 were reviewed. The inclusion criteria stated that the patients with early-stage (T1-T2NOM0) NSCLC lung cancer or oligometastatic lung cancer (IVa stage) were eligible for participation in this study. NSCLC (including carcinoma, adenocarcinoma, large cell carcinoma, and mixed cell carcinoma) in all patients was confirmed by histology. However, patients with several tumors in the lung were excluded from the analysis.

\section{Radiotherapy}

Patients were immobilized by TMPs (Klarity Medical Products, Newark, NJ, USA) or VCSs (Klarity Medical Products, Newark, NJ, USA) [13]. The patients were positioned in the immobilization device with the arms placed above the head. In the simulation, free breathing and 4D-CT (Philips Brilliance CT Big Bore, USA) were undertaken. The scan encompassed the upper margin of the second cervical spine up to the lower margin of the second lumbar spine with 3-5 mm layer thickness. The inhalation and exhalation correlated datasets were identified and transferred to the treatment planning system (RayStation Launcher 4.5.1, RaySearch Laboratories AB, Sweden or Philips Pinnacle 9.2 treatment planning system, Amsterdam, The Netherlands) for delineation of the gross tumor volume (GTV). The time phase interval of respiration in 4D-CT scanning was $10 \%$ with 10 images of the respiratory time phase on each layer. Furthermore, lung window and mediastinal window were compared. The GTV was contoured phase-by-phase referring to the result of chest CT or PET/CT. No margin was applied to the GTV to generate the clinical target volume (CTV). The GTV inhale and GTV exhale were fused to generate the internal tumor volume (ITV). The planning target volume (PTV) expanded 5-8 $\mathrm{mm}$ in every direction based on the ITV range. Moreover, organs at risk (OAR) including spinal cord, bilateral lungs, trachea, chest wall, brachial plexus, heart, and esophagus were contoured. The conformality and dose limits of normal tissues were set according to RTOG0236 [14]. The treatment requirements for large lesions (maximum cross-sectional diameter $>4 \mathrm{~cm}$ ) or adjacent vital organs were satisfied by reducing the dose in each fraction and 
increasing the number of fractions. In the treatment, $80 \%$ iso-dose line was used as the prescribed dose to cover 95\% PTV, and 100\% iso-dose line was used to cover 100\% ITV. The fraction dose was 5-15Gy. Patients received $4-10$ SBRT fractions (mean $=5$ ) by $6 \mathrm{MV} \mathrm{X}$-ray in 6-14 fields using the coplanar technique IMRT or volumetric modulated arc therapy (VMAT) (ElektaSynergy $^{\text {tm }}$, Stockholm, Sweden) or Varian Trilogy-SN5387 linear accelerator (Varian Medical Systems Inc., Palo Alto, CA, USA).

\section{CBCT and data collection}

For initial treatment, the patients were set up to isocenter with in-room lasers and skin tattoos. Then, $\mathrm{CBCT}$ scanning was conducted in a $360^{\circ}$ standard rotation mode. First, a rigid registration of the bony anatomy was performed to assess rotation, initiating the patient resetup by therapists if $\mathrm{a} \pm 3^{\circ}$ rotational tolerance was exceeded. The manual registration of the ITV contour was performed with respect to patient's tumor and softtissue target after the rotational parameters were measured within the tolerance limits. The data on the shifts were obtained from On Bio-rad Imager 1.6 system (Varian Medical Systems Inc., Baden, Switzerland), and cross-sectional, sagittal, and coronal CT images were obtained by analysis and reconstruction (automatic registration function equipped with OBI 1.6 software). The grayscale registration was conducted on areas including the tumor, the surrounding tissue, and vital organs at risk. The shifts from the first couch were adjusted accordingly. The tolerance of CBCT for treatment at our institute was 5,5 , and $5 \mathrm{~mm}$ in left-right, $\mathrm{AP}$, and $\mathrm{CC}$ directions, respectively. Those exceeding these limits required verification of $\mathrm{CBCT}$ when the shift was adjusted. The couch position from the first fraction treatment was used as the couch position for the other fractions. Subsequently, the treatment was performed, post-treatment CBCT scanning was conducted after the treatment, and intrafraction setup errors data were obtained.

\section{Statistical analysis}

The setup errors included translational errors in the ML direction, CC direction, and AP direction. The mean and standard deviation of the translational errors were calculated. The multiple groups were compared by analysis of variance (ANOVA), while the pairwise comparison of the mean was conducted by LSD test. The difference in the ratio was compared by chi-square test. The expanded value from ITV to PTV was calculated by the expansion equation of the CTV to PTV as proposed by van Herk: PTV $=2.5 \times$ mean $+0.7 \times$ standard deviation (13), which was considered to be statistically significant if bilateral $P<0.05$. All data were analyzed using SPSS (Statistics version 21, SPSS Inc. IBM, Chicago, IL).

\section{Results}

Correlation between interfraction setup errors and clinical factors

The 687 CBCT scans were collected from a cohort of 121 patients. In total, 60 patients received IMRT, while 61 patients received VMAT. Subsequently, 26 patients received $12.5 \mathrm{~Gy} \times 4$ fractions, 91 received $10 \mathrm{~Gy} \times 5$ fractions, 1 received $7.5 \mathrm{~Gy} \times 8$ fractions, 2 received $7 \mathrm{~Gy} \times 10$ fractions, and 1 received $6 \mathrm{~Gy} \times 10$ fractions. The interfraction setup errors of patients are shown in Table 1.

As shown in Table 1, no correlation was established in the maximum interfraction setup errors in any direction irrespective of the factors such as the age, educational status, lesion location (left upper lobe, left lower lobe, right upper lobe, right middle lobe, right lower lobe), patients from rural or urban areas, body mass index (BMI), Karnofsky performance status (KPS), and methods of immobilization.

A rigid registration of the bones was performed to assess the patient's rotation error. A total of 228 rotational errors were recorded. The possibility of exceeding the rotational tolerance $\left(>3^{\circ}\right)$ was $0.6 \%$ for those immobilized by TMP, and $2.0 \%$ for by VCS. However, no difference was detected while using different immobilization devices ( $P=0.398$, OR $0.28,95 \%$ CI: 0.02-4.62).

Thus, the setup errors in the ML, CC, and AP directions were less than a specific value, otherwise, $\mathrm{CBCT}$ necessitates verification. For example, if the CBCT required verification when the setup error was $>5 \mathrm{~mm}$, then that in the ML, CC, and AP directions satisfying the initial $\mathrm{CBCT}<6 \mathrm{~mm}$ were $95.3,89.5$, and $91.4 \%$, respectively. The setup error $<6 \mathrm{~mm}$ in any direction was potentially $78.6 \%$, while $21.4 \%$ was the probability of the necessity of CBCT verification (Fig. 1).

\section{Interfraction setup errors stratified by immobilization and BMI}

The patients were divided into two groups: $\mathrm{BMI}<24$ and $B M I \geq 24$. The effects of different ways of immobilization on the interfraction setup errors after grouping were compared and the probability of CBCT verification was calculated. In the group with $\mathrm{BMI} \geq 24$, the setup error in the ML direction immobilized by TMP was $1.4 \pm 1.2$ $\mathrm{mm}$, which was lower than that of VCS $(2.4 \pm 2.0 \mathrm{~mm})$ $(P<0.001)$. The setup errors in the CC and AP directions immobilized by TMP were $2.0 \pm 1.9 \mathrm{~mm}$ and $2.4 \pm 1.4 \mathrm{~mm}$, respectively, which did not differ significantly as compared to those by VCS $(2.0 \pm 1.9 \mathrm{~mm}$ in the CC direction, $P=0.917 ; 2.6 \pm 2.1 \mathrm{~mm}$ in the AP direction, $P=0.546$; Fig. 2 ).

In the group with $\mathrm{BMI}<24$, the interfraction setup error in the CC direction immobilized by VCS was $2.2 \pm 2.2 \mathrm{~mm}$, which was significantly lower as compared to the TMP $(2.9 \pm 2.3 \mathrm{~mm} ; P=0.001)$. However, the interfraction setup 
Table 1 Summary of positional error stratified by patient related factors

\begin{tabular}{|c|c|c|c|c|}
\hline \multirow[t]{2}{*}{ Patient related factor } & \multirow[t]{2}{*}{$N(P t s)$} & \multicolumn{3}{|c|}{ Positional error (mean \pm deviation, mm) } \\
\hline & & $\mathrm{ML}$ & CC & AP \\
\hline \multicolumn{5}{|l|}{ Age } \\
\hline$\geq 70$ & 57 & $1.9 \pm 1.8$ & $2.4 \pm 2.3$ & $2.3 \pm 2.0$ \\
\hline$<70$ & 64 & $2.1 \pm 1.7$ & $2.4 \pm 2.2$ & $2.2 \pm 2.0$ \\
\hline \multicolumn{5}{|l|}{ Primary sites } \\
\hline Left upper lobe & 33 & $2.0 \pm 1.8$ & $2.7 \pm 2.5$ & $2.1 \pm 2.0$ \\
\hline Left lower lobe & 17 & $1.8 \pm 1.7$ & $2.9 \pm 2.5$ & $2.1 \pm 1.8$ \\
\hline Right upper lobe & 29 & $2.0 \pm 1.6$ & $1.9 \pm 1.6$ & $2.4 \pm 2.2$ \\
\hline Right middle lobe & 18 & $1.4 \pm 1.4$ & $2.4 \pm 2.3$ & $2.1 \pm 1.7$ \\
\hline Right lower lobe & 24 & $2.4 \pm 1.8$ & $2.2 \pm 1.9$ & $2.0 \pm 1.8$ \\
\hline \multicolumn{5}{|l|}{ Education } \\
\hline Illiterate & 39 & $2.0 \pm 1.9$ & $2.1 \pm 2.0$ & $2.2 \pm 2.0$ \\
\hline Primary school & 37 & $1.9 \pm 1.6$ & $2.1 \pm 2.0$ & $2.4 \pm 2.1$ \\
\hline Middle school & 28 & $1.9 \pm 1.7$ & $2.6 \pm 2.3$ & $2.0 \pm 1.5$ \\
\hline High school & 8 & $2.7 \pm 2.1$ & $3.0 \pm 2.3$ & $2.8 \pm 2.5$ \\
\hline University qualifications & 9 & $2.3 \pm 1.6$ & $3.2 \pm 2.8$ & $2.7 \pm 2.2$ \\
\hline \multicolumn{5}{|l|}{ Urban/Rural } \\
\hline Urban & 54 & $2.2 \pm 1.8$ & $2.4 \pm 2.3$ & $2.4 \pm 2.0$ \\
\hline Rural & 67 & $1.9 \pm 1.7$ & $2.3 \pm 2.1$ & $2.2 \pm 1.9$ \\
\hline \multicolumn{5}{|l|}{ KPS } \\
\hline$>80$ & 84 & $2.0 \pm 1.5$ & $2.2 \pm 2.3$ & $1.1 \pm 1.0$ \\
\hline$\leq 80$ & 17 & $1.5 \pm 1.9$ & $2.1 \pm 2.0$ & $2.2 \pm 1.9$ \\
\hline \multicolumn{5}{|l|}{ Gender } \\
\hline Male & 88 & $2.0 \pm 1.8$ & $2.1 \pm 2.0$ & $2.3 \pm 2.0$ \\
\hline Female & 33 & $1.9 \pm 1.7$ & $3.1 \pm 2.6$ & $2.3 \pm 1.8$ \\
\hline \multicolumn{5}{|l|}{ Immobilization } \\
\hline Thermoplastic masks & 43 & $1.6 \pm 1.3$ & $2.8 \pm 2.3$ & $2.0 \pm 1.7$ \\
\hline Vacuum cushion & 78 & $2.2 \pm 2.0$ & $2.2 \pm 2.1$ & $2.4 \pm 2.1$ \\
\hline \multicolumn{5}{|l|}{ BMI } \\
\hline $\mathrm{BMI}<18.5$ & 16 & $1.9 \pm 1.7$ & $2.3 \pm 2.1$ & $2.0 \pm 1.7$ \\
\hline $18.5 \leq \mathrm{BMI}<24$ & 65 & $2.0 \pm 1.7$ & $2.5 \pm 2.3$ & $2.1 \pm 2.0$ \\
\hline $\mathrm{BMI} \geq 24$ & 40 & $2.1 \pm 1.8$ & $2.0 \pm 1.9$ & $2.6 \pm 1.9$ \\
\hline
\end{tabular}

Abbreviations: Pts = patients; $\mathrm{ML}=$ medial-lateral; $\mathrm{CC}=$ cranial-caudal $; \mathrm{AP}=$ anterior-posterior

error in the AP direction immobilized by TPM was $1.8 \pm 1.8 \mathrm{~mm}$, which was significantly lower as compared to that by VCS $(2.3 \pm 2.0 \mathrm{~mm} ; P=0.006)$. Furthermore, no significant difference was observed in the ML direction between TMP and VCS $(1.8 \pm 1.4$ $\mathrm{mm}$ in the CC direction vs. $2.1 \pm 1.8 \mathrm{~mm}$ in the AP direction; $P=0.098$; Fig. 3).

Furthermore, the acceptable setup errors in each direction did not exceed a specific value, or else, CBCT would require verification. The correlation between acceptable errors and rate in the ML, CC, and AP direction immobilized by VCS or TMP is shown (Fig. 4).

\section{Intrafraction setup error}

A total of 126 CBCT scans from 29 patients before and after radiotherapy were collected. The relative displacements before and after the treatment were $0.9 \pm 1.0 \mathrm{~mm}$ in the ML direction, $1.1 \pm 1.5 \mathrm{~mm}$ in the CC direction, and $1.2 \pm 1.2 \mathrm{~mm}$ in the AP direction. The required expansions of PTV are listed (Table 2) according to different recipes. A total of 22 patients in the cohort used TMP, and the displacements during the treatment were $0.9 \pm 1.0 \mathrm{~mm}$ in the ML direction, $1.1 \pm 1.3 \mathrm{~mm}$ in the $\mathrm{CC}$ direction, and $1.2 \pm 1.2 \mathrm{~mm}$ in the AP direction. On the other hand, 7 patients used VCS, and displacements were $1.3 \pm 1.3 \mathrm{~mm}$ in the ML direction, $1.6 \pm 2.2 \mathrm{~mm}$ in 

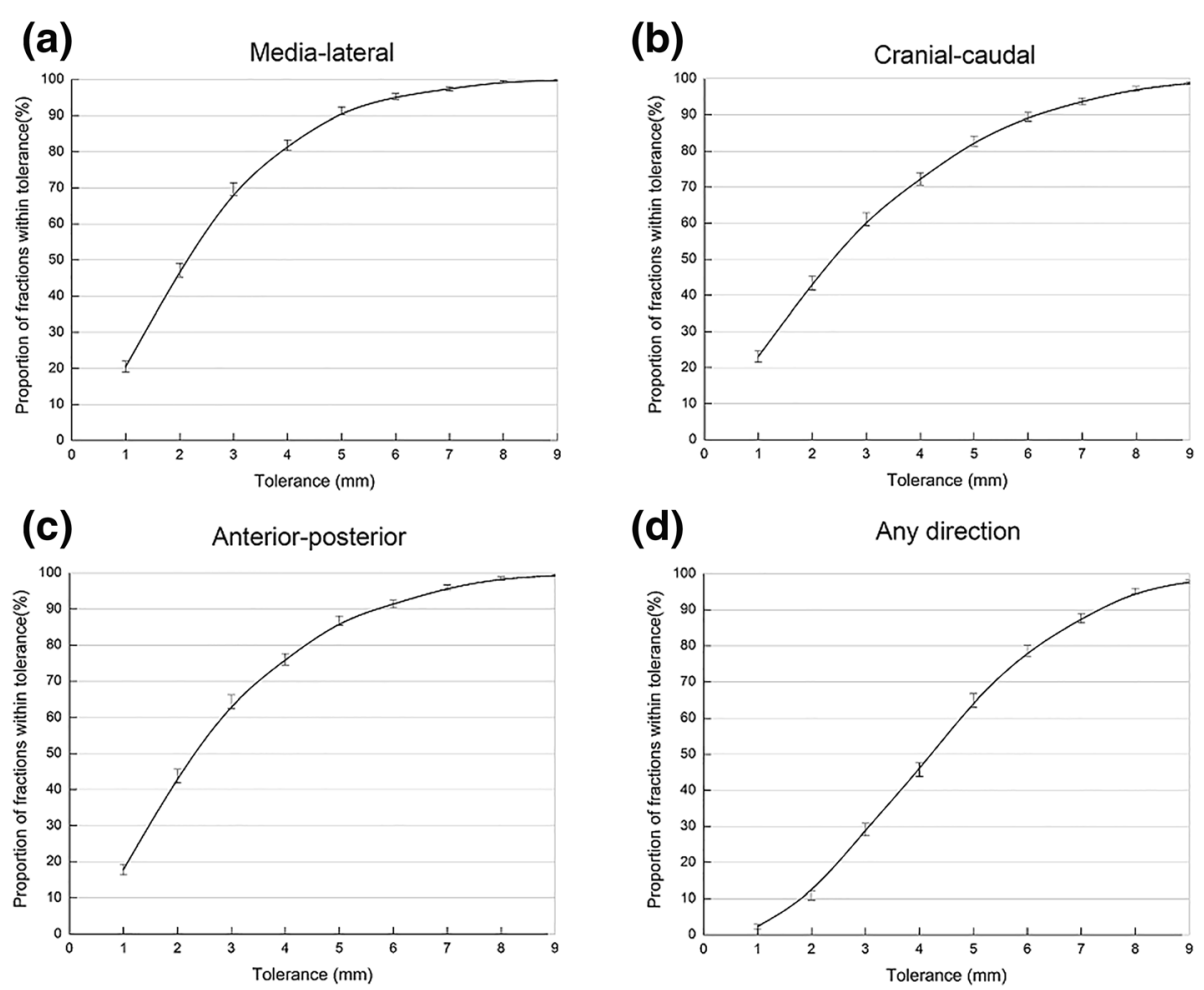

Fig. 1 Proportion of treatment fractions within tolerance measured based on the cone-beam computed tomography (CBCT) scans in a mediallateral direction, $\mathbf{b}$ cranial-caudal direction, $\mathbf{c}$ anterior-posterior direction, $\mathbf{d}$ any direction ( $N=121$ patients)

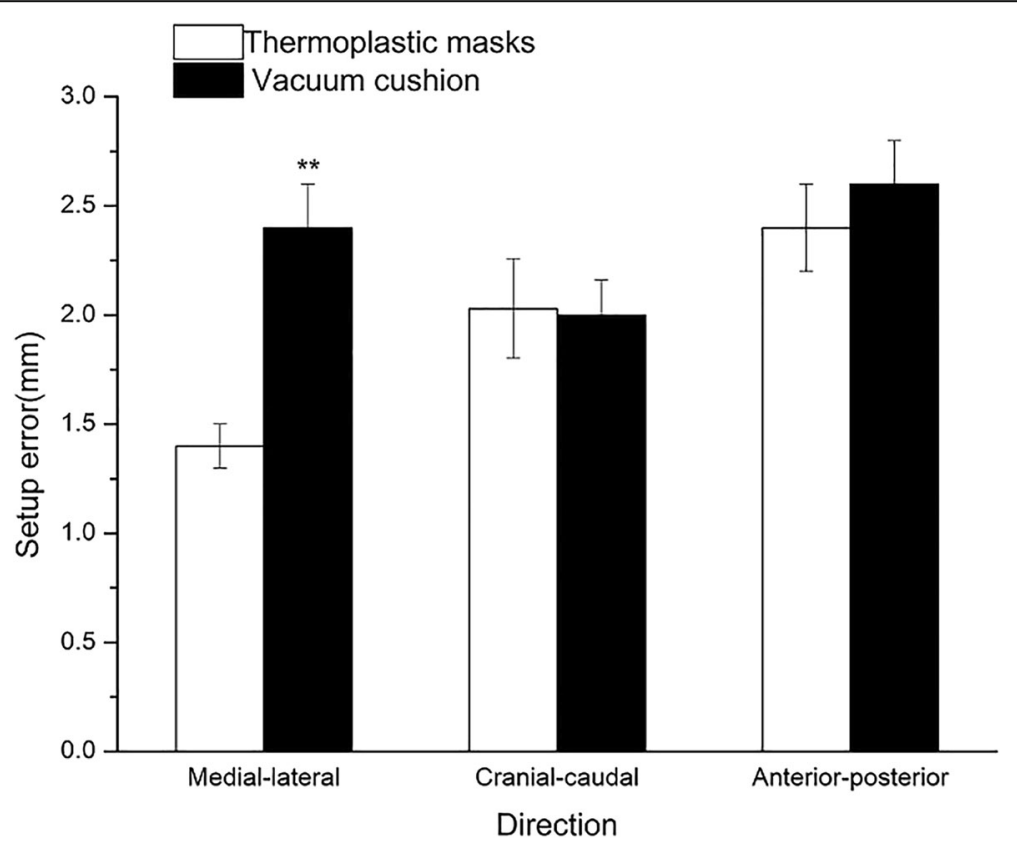

Fig. 2 Set-up error stratified by immobilization type in patients with BMI $\geq 24$ 


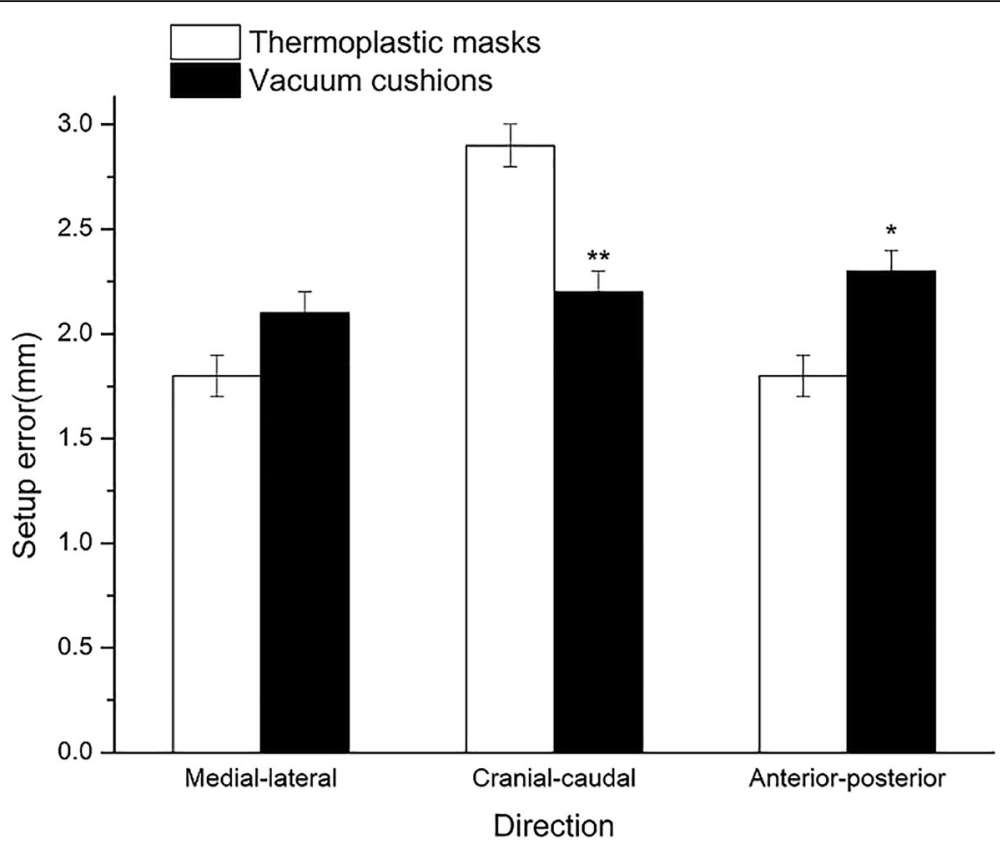

Fig. 3 Set-up error stratified by immobilization type in patients with $\mathrm{BMI}<24$

the $\mathrm{CC}$ direction, and $1.6 \pm 1.3 \mathrm{~mm}$ in the AP direction. However, no significant difference was noted in all relative displacements of patients when different ways of immobilization were employed during the treatment (all $P>0.05$ ).

\section{Discussion}

Since the SBRT fraction dose is relatively high and the dose of the surrounding normal tissues declines rapidly, the accuracy and high-dose radiation to tumor tissues, as well as the maximum protection of the surrounding normal tissues can be ensured by the SBRT setup. Therefore, an adequate immobilization device is critical, which might reduce the interfractional and intrafractional setup errors.

Nevertheless, the localization of CBCT (localization $\mathrm{CBCT}$ ) should be performed after the patients are positioned in the treatment bed. If significant errors were found during localization $\mathrm{CBCT}$, then further verification of $\mathrm{CBCT}$ should be conducted. During the treatment, an additional CBCT (intrafraction CBCT) may be needed to ensure the proper range of PTV for the target areas. Subsequently, the treatment is suspended if errors are detected; nonetheless, it is continued after reset. Then, a post-treatment $\mathrm{CBCT}$ was performed in order to assess the large displacement during the treatment [11].

However, the longer the patients lie in the treatment bed in a specific posture, the more likely are the displacements to occur. Moreover, SBRT is usually required by elderly patients with poor pulmonary functions $[15,16]$; the shortening of the treatment duration is very important. In addition, abundant $\mathrm{CBCTs}$ increases the expense of the patients and workload of the technicians.

The widespread application of SBRT based on VMAT technology results in a $37-63 \%$ shortening of the treatment time $[17,18]$. Thus, intrafraction CBCT in patients with a short treatment time might not be essential [19].

In order to reduce the frequency of verification $\mathrm{CBCT}$, a majority of the centers stated that the verification CBCT should be conducted if errors are less than a specific value [9]. For example, our center postulates that the verification $\mathrm{CBCT}$ should be performed to revise the position, only if the bed moves greater than $5 \mathrm{~mm}$ [13].

The immobilization methods might affect the setup errors $[19,20]$. Nevertheless, relatively few studies addressed the immobilization techniques. Several studies compared the effects of abdominal compression and VCS on SBRT setup error and did not find any difference $[9,10,12]$. Moreover, $\mathrm{Li}$ et al. [9] did not detect any differences while comparing the effects of abdominal compression, chest board, and VCS on setup errors. Furthermore, Navarro-Martin et al. compared the effects of TMP and VCS on SBRT and demonstrated that the setup errors of TMP were smaller and more favored by patients than VCS [10]. However, these studies did not compare the effects of different immobilization devices by combining the characteristics of the patients (physique). Patients with slim bodies (such as most Asian patients) have different feelings of comfort to TMP as compared to those with plump bodies. Although it has not yet been reported, the effects of different immobilization devices on the setup errors of patients with different physiques might 

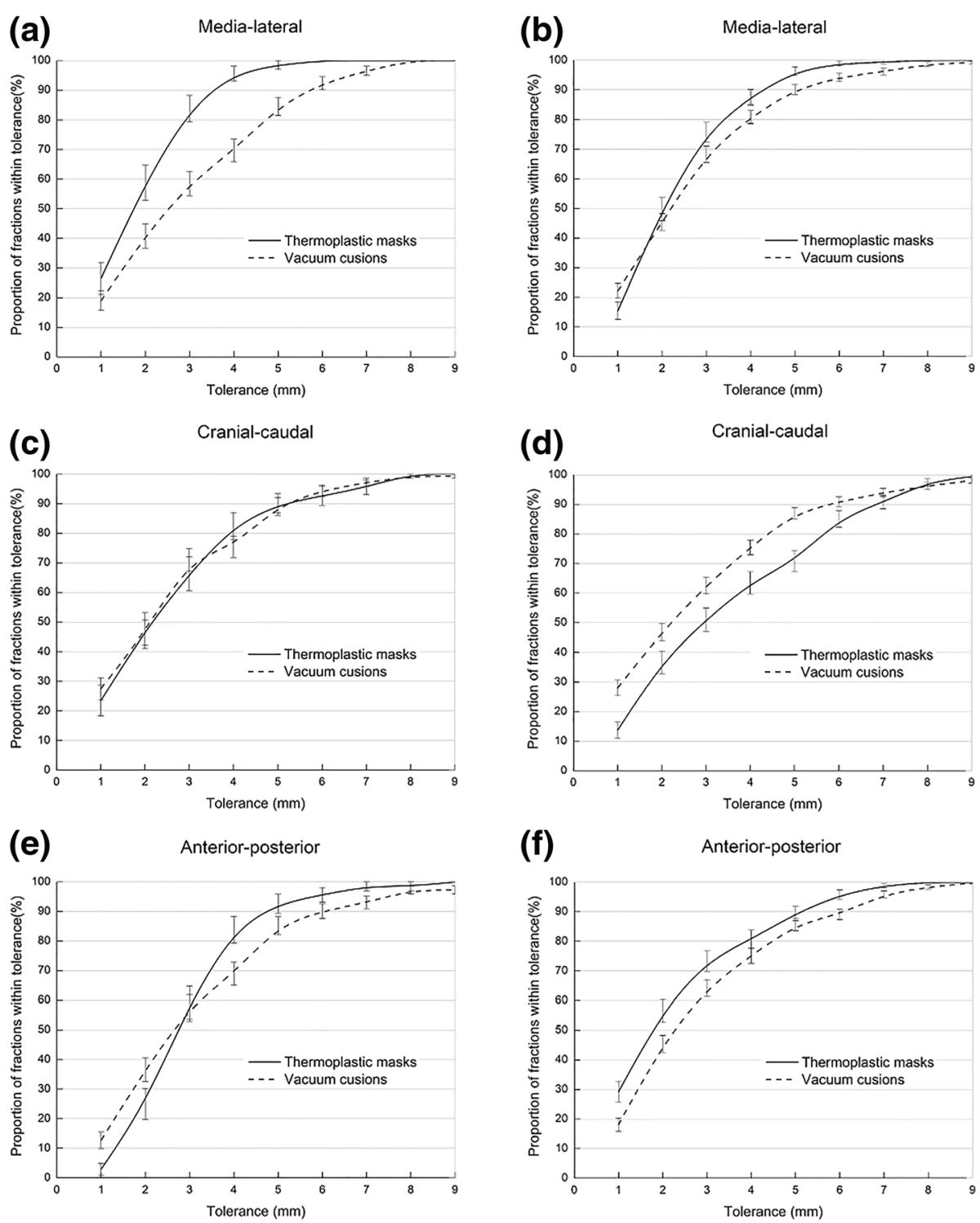

For patients with $\mathrm{BMI} \geq 24$

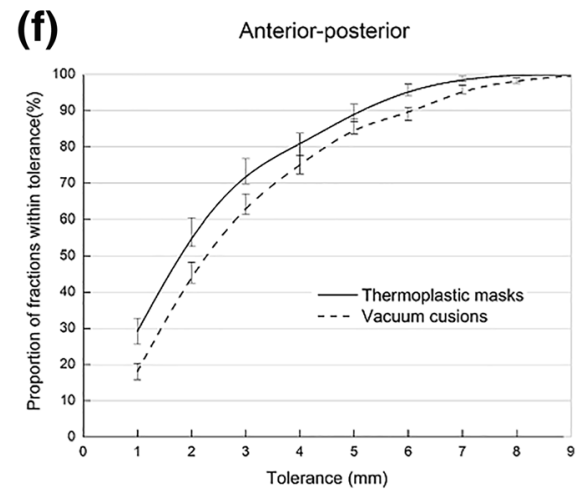

For patients with $\mathrm{BMI}<24$

Fig. 4 Proportion of treatment fractions within tolerance stratified by immobilization type and BMI. a Medial-lateral direction in patients with BMI $\geq 24$; b Medial-lateral direction in patients with $\mathrm{BMI}<24$; c Cranial-caudal direction in patients with BMI $\geq 24$; d Cranial-caudal direction in patients with $\mathrm{BMl}<24$; e Anterior-posterior direction in patients with $\mathrm{BMI} \geq 24$; $\mathbf{f}$ Anterior-posterior direction in patients with $\mathrm{BMl}<24$ ( $N=121$ patients)

Table 2 PTV margin changes of lung tumor patients

\begin{tabular}{lllll}
\hline Author & Recipe & \multicolumn{3}{l}{$\mathrm{PTV}$ margin $(\mathrm{mm})$} \\
\cline { 3 - 5 } & & $\mathrm{ML}$ & $\mathrm{CC}$ & $\mathrm{AP}$ \\
\hline Stroom et al. & $2 \Sigma+0.7 \sigma$ & 2.5 & 3.3 & 3.2 \\
van Herk et al. & $2.5 \Sigma+0.7 \sigma$ & 3.0 & 3.8 & 3.8 \\
Parker et al. & $\Sigma+\sqrt{\sigma^{2}+\Sigma^{2}}$ & 2.2 & 3.0 & 2.9 \\
Snoke JJ & $2.5 \sum+\beta(\sigma 2+\sigma \mathrm{P}$ & 2.7 & 3.6 & 3.6 \\
& $2)^{1 / 2}-\beta \sigma P$ & & & \\
\hline
\end{tabular}

Abbreviations: $M L$ medial-lateral, CC cranial-caudal, $A P$ anterior-posterior Symbols: $\Sigma$, standard deviation of systematic uncertainties; $\sigma$, standard deviation of statistical (random) uncertainties. $\sigma P=0.64, \beta=0.84$ be varied. To investigate the above questions of body sizes, our study designed two patient groups based on $\mathrm{BMI}<$ or $>24$. Subsequently, the errors in various directions under different immobilization devices were analyzed between patients with slim and plump bodies. The current study found that errors (2.2 vs. $2.9, P=0.001)$ in the $\mathrm{CC}$ direction were small in the case of patients with slim bodies $(\mathrm{BMI}<24)$ immobilized by VCS, which might be attributed to the correlation between the hand gesture and errors in that direction. Therefore, the usage of hands was rather comfortable with superior repeatability upon the usage of VCSs. The errors in the AP direction were 
slightly larger (2.3 mm in VCSs vs. $1.8 \mathrm{~mm}$ in TMPs); however, SBRT was frequently used in elderly patients, and elderly Chinese patients with slim bodies were often accompanied with humps. Thus, such patients would be rather comfortable if VCSs were used, and hence, it is recommended for patients with slim bodies.

The current study demonstrated that immobilization effects were satisfactory if TMPs were used for patients with plump bodies (BMI $\geq 24)$. Compared to VCSs, the setup errors were reduced in the ML direction (1.4 vs. $2.4 \mathrm{~mm} ; P<0.001$ ), while those in the $C C$ direction were similar to the errors in the AP direction. Therefore, the possibility of a repeat verification $\mathrm{CBCT}$ was shortened in these patients, thereby preferring the immobilization by TMPs for patients with plump bodies.

Furthermore, the displacement during the treatment was not significantly different irrespective of VCS or TMP. Thus, it can be concluded that the displacements of patients during the treatment were not affected by the immobilization devices [21]. In summary, we proposed that different immobilization devices should be used based on the BMI of patients by analyzing the setup errors of patients with different physiques using various immobilization devices. The current study recommended the use of VCS for patients with $\mathrm{BMI}<24$ and TMP for patients with $\mathrm{BMI} \geq 24$. However, no significant difference was observed in the errors of treatment between the two immobilization masks. Nevertheless, this retrospective study also presented some limitations. Firstly, the time of each treatment was not recorded and it might also affect the displacements of patients before and after the treatment. Secondly, approximately, $67 \%$ of the data on rotational errors were missing during analysis. Next, the patient's comfort and tolerance have not been yet considered in the present study. Although the conclusions of this study were not affected, the effects of additional factors (including treatment time and the feeling of pain) on the setup errors and immobilization devices should be investigated in order to promote a sophisticated process of SBRT and improve the service provided to the patients.

\section{Conclusion}

The immobilization choice of SBRT for lung tumors depends on the BMI of the patients. For patients with $\mathrm{BMI} \geq 24$, TMP offers a better reproducibility; however, VCS may be preferable for the patients with $\mathrm{BMI}<24$. Further study is needed.

\section{Abbreviations}

4D-CT: four-dimensional computed tomography; AP: Anterior-posterior; BMI: Body mass index; CBCT: Cone Beam Computed Tomography; CC: Cranial-caudal; GTV: Gross tumor volume; ITV: Internal tumor volume; KPS: Karnofsky performance status; ML: Medial-lateral; OAR: Organs at risk; PTV: Plan target volume; SBRT: Stereotactic radiotherapy; TMP: Thermoplastic masks; VCS: Vacuum cushion

\section{Acknowledgements}

Not applicable.

\section{Authors' contributions}

CG: data collection, statistical analysis, and writing and revising the manuscript. DB, SG, ZX, TH: statistical analysis and revising the manuscript. $L Y, W Z, X W, X G, Y G, Z F$ : patient administration, and data collection. HX, YJ, $X Y$ : patient administration, and critical revision of the manuscript. WJ and CM study design, statistical analysis, critical revision of the manuscript and funds collection. All authors gave final approval of the version to be published.

\section{Funding}

This study was supported by grants from the National Natural Science Foundation of China 81672972. This catered for statistical analysis. The authors have no conflict of interest with respect to this manuscript.

\section{Availability of data and materials}

The datasets used and/or analyzed during the current study are available from the corresponding author on reasonable request.

\section{Ethics approval and consent to participate}

The study was approved by our hospital's institutional review board, and a written informed consent was given by all patients.

The present study was approved by the Ethics Committee and Institutional Review Board of Zhejiang Cancer Hospital; the committee's reference Number: IRB-2018-153(Ke)

\section{Consent for publication}

Not applicable.

\section{Competing interests}

The authors declare that they have no competing interests.

\section{Author details}

${ }^{1}$ Department of Radiation Oncology, Zhejiang Cancer Hospital, 1st Banshan East Road, Hangzhou 310022, China. ${ }^{2}$ Zhejiang Provincial Key Laboratory of Radiation Oncology, Hangzhou 310022, China. ${ }^{3}$ People's hospital of Yuxi city in Yunnan province, Yuxi 653100, China. ${ }^{4}$ Yitu Healthcare, Shanghai, China.

Received: 2 June 2018 Accepted: 29 May 2019

Published online: 14 June 2019

\section{References}

1. Chi A, Liao Z, Nguyen N, Xu J, Stea B, Komaki R. Systemic review of the patterns of failure following stereotactic body radiation therapy in early-stage non-small-cell lung cancer: clinical implications. Radiother Oncol. 2010;94:1-11.

2. Baumann P, Nyman J, Hoyer M, Gagliardi G, Lax I, Wennberg B, et al. Stereotactic body radiotherapy for medically inoperable patients with stage I non-small cell lung cancer - a first report of toxicity related to COPD/CVD in a non-randomized prospective phase II study. Radiother Oncol. 2008;88: 359-67.

3. Solda F, Lodge M, Ashley S, Whitington A, Goldstraw P, Brada M. Stereotactic radiotherapy (SABR) for the treatment of primary non-small cell lung cancer; systematic review and comparison with a surgical cohort. Radiother Oncol. 2013;109:1-7.

4. Murray L, Ramasamy S, Lilley J, Snee M, Clarke K, Musunuru H, et al. Stereotactic ablative radiotherapy (SABR) in patients with medically inoperable peripheral early stage lung Cancer: outcomes for the first UK SABR cohort. Clin Oncol (R Coll Radiol). 2016:28:4-12.

5. Takeda A, Kunieda E, Ohashi T, Aoki Y, Koike N, Takeda T. Stereotactic body radiotherapy (SBRT) for oligometastatic lung tumors from colorectal cancer and other primary cancers in comparison with primary lung cancer. Radiother Oncol. 2011:101:255-9.

6. Onishi $H$, Shirato $H$, Nagata $Y$, Hiraoka M, Fujino M, Gomi K, et al. Hypofractionated stereotactic radiotherapy (HypoFXSRT) for stage I nonsmall cell lung cancer: updated results of 257 patients in a Japanese multiinstitutional study. J Thorac Oncol. 2007;2:S94-100.

7. Nagata Y, Takayama K, Matsuo Y, Norihisa Y, Mizowaki T, Sakamoto T, et al. Clinical outcomes of a phase I/II study of 48 Gy of stereotactic body radiotherapy in 4 fractions for primary lung cancer using a stereotactic body frame. Int J Radiat Oncol Biol Phys. 2005;63:1427-31. 
8. Uematsu M, Shioda A, Suda A, Fukui T, Ozeki Y, Hama Y, et al. Computed tomography-guided frameless stereotactic radiotherapy for stage I nonsmall cell lung cancer: a 5-year experience. Int J Radiat Oncol Biol Phys. 2001:51:666-70.

9. Li W, Purdie T, Taremi M, Fung S, Brade A, Cho B, et al. Effect of immobilization and performance status on intrafraction motion for stereotactic lung radiotherapy: analysis of 133 patients. Int J Radiat Oncol Biol Phys. 2011;81:1568-75.

10. Navarro-Martin A, Cacicedo J, Leaman O, Sancho I, García E, Navarro V, et al. Comparative analysis of thermoplastic masks versus vacuum cushions in stereotactic body radiotherapy. Radiat Oncol. 2015;10:176.

11. Rossi M, Peulen H, Belderbos J, Sonke J. Intrafraction motion in stereotactic body radiation therapy for non-small cell lung Cancer: intensity modulated radiation therapy versus volumetric modulated arc therapy. Int J Radiat Oncol Biol Phys. 2016;95:835-43.

12. Sio $T$, Jensen A, Miller R, Fong de los Santos L, Hallemeier C, Foster N, et al. Influence of patient's physiologic factors and immobilization choice with stereotactic body radiotherapy for upper lung tumors. J Appl Clin Med Phys. 2014;15:4931.

13. van Herk M. Errors and margins in radiotherapy. Semin Radiat Oncol. 2004 $14: 52-64$.

14. Timmerman R, Paulus R, Galvin J, Michalski J, Straube W, Bradley J, et al. Stereotactic body radiation therapy for inoperable early stage lung Cancer. JAMA. 2010;303:1070-6.

15. Stanic S, Paulus R, Timmerman RD, Michalski JM, Barriger RB, Bezjak A, et al. No clinically significant changes in pulmonary function following stereotactic body radiation therapy (SBRT) for early stage peripheral nonsmall cell lung Cancer: an analysis of RTOG 0236. Int J Radiat Oncol Biol Phys. 2014;88:1092-9.

16. Hayashi S, Tanaka H, Kajiura Y, Ohno Y, Hoshi H. Stereotactic body radiotherapy for very elderly patients (age, greater than or equal to 85 years) with stage I non-small cell lung cancer. Radiat Oncol. 2014;9:138.

17. Holt A, van Vliet-Vroegindeweij C, Mans A, Belderbos JS, Damen EM. Volumetric-modulated arc therapy for stereotactic body radiotherapy of lung tumors: a comparison with intensity-modulated radiotherapy techniques. Int J Radiat Oncol Biol Phys. 2011;81:1560-7.

18. Weyh A, Konski A, Nalichowski A, Maier J, Lack D. Lung SBRT: dosimetric and delivery comparison of RapidArc, TomoTherapy, and IMR. J Appl Clin Med Phys. 2013;14:4065.

19. Li R, Han B, Meng B, Maxim PG, Xing L, Koong AC, et al. Clinical implementation of intrafraction cone beam computed tomography imaging during lung tumor stereotactic ablative radiation therapy. Int J Radiat Oncol Biol Phys. 2013;87:917-23.

20. Richmond ND, Pilling KE, Peedell C, Shakespeare D, Walker CP. Positioning accuracy for lung stereotactic body radiotherapy patients determined by on-treatment cone-beam CT imaging. Br J Radiol. 2012;85:819-23.

21. Mathew L, Swaminath A, Szabo J, Wierzbicki M. Sci-Thur AM: planning - 06: planning target volume margin suitability in lung stereotactic body radiation therapy: a preliminary evaluation using cone-beam computed tomography. Med Phys. 2012;39:4620.

\section{Publisher's Note}

Springer Nature remains neutral with regard to jurisdictional claims in published maps and institutional affiliations.

\section{Ready to submit your research? Choose BMC and benefit from:}

- fast, convenient online submission

- thorough peer review by experienced researchers in your field

- rapid publication on acceptance

- support for research data, including large and complex data types

- gold Open Access which fosters wider collaboration and increased citations

- maximum visibility for your research: over $100 \mathrm{M}$ website views per year

At BMC, research is always in progress.

Learn more biomedcentral.com/submissions 